\title{
DA ARTE DE FAZER-SE VIRTUOSA: REGIMENTOS DE PRINCESAS (CASTELA, SÉCULO XV)
}

\section{the art of making oneself virtuous: Regiments of princesses (CastIIE, 15th century)}

\author{
Danielle Oliveira Mércuri \\ Doutora em História e Cultura Social pela Faculdade de Ciências Humanas e Sociais de Franca \\ (UNESP- Franca) \\ Professora Orientadora na Universidade Federal de São Paulo (UNIFESP)-UAB \\ dani_mercuri@yahoo.com.br \\ ORCID: https://orcid.org/0000-0002-3918-7744
}

Recebido em: 31/10/2019

Aprovado em: 15/05/2020

\begin{abstract}
Resumo : Comumente escritos para prescrever aos príncipes como estes deveriam se conduzir e em quais exemplos deveriam se mirar, os specula principum concederam um papel relativamente secundário às mulheres. Ainda que os espelhos tenham prescrito, a partir das indicações apresentadas aos príncipes, a conduta das infantas e consortes, nenhum deles parece ter indicado diretamente as mulheres como público-alvo de seus ensinamentos, nem mesmo contemplado a relação entre mulher, coroa e poder. No entanto, na segunda metade do século $\mathrm{XV}$, frente a possibilidade que se apresentou no reino castelhano de que a coroa fosse herdada e regida por uma mulher, bem como o imperativo de que a ordem e a boa condução do reino não fossem mais colocadas em risco pelos erros e vícios cometidos pelas rainhas, despertou o interesse e a urgência de que também elas fossem instruídas sobre como deveriam se conduzir. Nesse sentido, nosso fito neste artigo será analisar e cotejar alguns roteiros de governo preparados especialmente pelos clérigos Martín de Córdoba, Íñigo de Mendoza e Hernando de Talavera, que foram endereçados à rainha Isabel (1451-1504).
\end{abstract}

\section{Palavras-chave: Castela- Regimentos- Princesa- Mulheres.}

Abstract: Commonly written to dictate how princes should behave and which examples to look up to, the specula principum granted women a relatively minor role. Even though the models have dictated, based on the directions given to the princes, the conduct of infantes and consorts, none of them seem to have directly indicated women as the target audience of their teachings, not even contemplating the relationship among woman, crown and power. However, in the second half of the 15th century, given the possibility presented in the Castilian kingdom that the crown was inherited and ruled by a woman, as well as the need that the order and good conduct in the kingdom should no longer be put at risk by the mistakes and vices perpetrated by queens, aroused the interest and the urgency that they should also be instructed on how to behave. In this sense, our purpose in this article will be to analyze and collate some government scripts, especially the ones prepared by the clerics Martín de Córdoba, Íñigo de Mendoza and Hernando de Talavera, which were addressed to Queen Isabel (1451-1504).

Keywords: Castile- Regiments- Princess- Women. 


\section{Introdução}

Algumas das rainhas castelhanas do século $\mathrm{XV}$, segundo apontam os registros escritos, parecem não ter alcançado, entre os seus contemporâneos, uma imagem estimável. Dona Catarina de Lancaster (esposa de Enrique III), apesar de ter sido, nas palavras de Fernán Perez de Guzmán, "muito honesta, guardada em sua pessoa e fama, liberal e magnífica", teve um "vício muito comum entre os reis": "submeter-se às vontades dos privados", permitindo que eles a regessem (1941: 19). Conhecidas e criticadas eram as relações que a monarca tinha mantido, por exemplo, com uma de suas protegidas: Dona Leonor López de Córdoba (1362/63-1430), senhora cuja família havia prestado serviços ao avô da rainha, o rei D. Pedro I (FÉLIX BELLIDO, 2012: 97-100; GUIMARÃES, 2015). A esposa de Juan II, Dona Maria de Aragão, por sua vez, não obstante tivesse recebido elogios de alguns tratadistas, tinha, como enfatizaram os cronistas desse rei, atuado mais em favor de sua família aragonesa do que em conformidade com as vontades e os interesses castelhanos de seu marido (ÁLVAREZ PALENZUELA, 2006: 370). A essas mulheres, juntava-se Dona Juana, rainha consorte de Enrique IV, lembrada pelos cronistas por sua conduta depravada e por seus incentivos à promoção de atos viciosos no reino que haviam colocado em risco a legitimidade de sua filha, Dona Juana, como herdeira ao trono e filha de Enrique IV. É certo que, até então, ao passo que sobravam indicações e orientações acerca de como os príncipes e reis deveriam conduzir o governo de si, da casa e do reino (NOGALES RINCÓN, 2006: 9-39), minguadas eram as diretrizes dirigidas às rainhas.

Na Glosa Castellana al Regimiento de Príncipes de Egídio Romano - texto de larga repercussão no reino castelhano, tomado como referência para a instrução dos monarcas - e em outros espelhos de príncipes, as menções feitas às mulheres se restringiam ao que os homens, e em especial os reis, na condição de seus maridos, deveriam procurar ao escolhê-las. Eles eram instigados a buscar, através do matrimônio, laços familiares que ajudassem a fortalecer o reino, mulheres cultivadas nos bons costumes e fortes fisicamente que acrescentassem suas famas e lhes garantissem a perpetuidade de suas linhagens, dando-lhes descendentes saudáveis e legítimos. Não elas, mas sim eles eram os alvos destes tipos de instrução. Esses textos eram preparados para que eles fossem orientados acerca de um conjunto de diretrizes morais e de 
governo. Junto dos servos e dos filhos, elas eram mencionadas como um dos elementos que, por sua natureza inferior e debilidade, conferiam aos reis, poder, superioridade e autoridade para conduzir e governar.

Dito de outro modo, conquanto os espelhos prescrevessem, a partir das indicações apresentadas aos príncipes, o comportamento das infantas e consortes, nenhum deles havia indicado diretamente as mulheres como público-alvo de seus ensinamentos, nem mesmo contemplado a relação entre mulher, coroa e poder (HARO CORTÉS, 2009: 4344). No entanto, na segunda metade do século $X V$, a possibilidade que se apresentou no reino castelhano de que a coroa fosse herdada e regida por uma mulher, bem como o imperativo de que a ordem e a boa condução do reino não fossem mais colocadas em risco pelos erros e vícios cometidos pelas rainhas, despertou o interesse e a urgência de que também elas fossem esclarecidas e educadas sobre como deveriam se conduzir (CODET, 2014:121).

A ascensão de Isabel ao trono em 1474 mobilizou o preparo dos specula principum, gênero de textos que, até então, não tinha as rainhas como alvo. À feitura desses roteiros de governo se dedicaram especialmente os clérigos Martín de Córdoba, Íñigo de Mendoza e Hernando de Talavera. Por isso, a partir de um mapeamento das aproximações e dos distanciamentos dessas gramáticas de governo que foram endereçadas a D. Isabel, analisaremos quais foram as pautas de comportamento e as orientações para o regimento que estes clérigos prepararam para a rainha. ${ }^{1}$

\section{Recomendações}

Foi para compor o caráter de quem seria futuramente rainha que frei Martín de Córdoba $^{2}$ escreveu a Isabel apresentando-lhe e dedicando-lhe o Jardín de nobles doncellas. Conforme sugerem as menções feitas no prólogo deste texto, o frei possivelmente o preparou após a morte de Afonso, irmão mais novo de Isabel, e no momento em que a sucessão ao trono por ela tinha sido firmada pelo pacto de Toros de Guisando (1468). Quer dizer, além de instruir a princesa acerca de suas futuras funções apresentando-lhe uma espécie de compêndio das condições requeridas às nobres donzelas, o agostiniano dizia escrever com a motivação de justificar a legitimidade de 
direito da nova sucessora. ${ }^{3}$ Conforme sintetizou Martín de Córdoba dirigindo-se a Isabel:

[...] como no jardim de donzelas, mire vosso vivo entendimento e tome deleite, porque, já que a sucessão natural vos dá o regimento, que não faleça por defeito de sabedoria moral; antes a vossa aprovada sabedoria vos faça digna de reger, como vos faz digna a real e primogenitura do sangue. Onde, Senhora, quis tomar este trabalho de fazer um breve escrito que fale da geração, condição e composição das nobres donas; em especial, daquelas que são ou esperam ser rainhas, esperando deste trabalho só de Deus galardão, pelo qual os reis reinam e os servos são dignos de terem reis. Acrescento a isso, a grande benevolência que concedeu a mim o senhor de gloriosa memória, o rei D. Afonso, vosso irmão, e a grande devoção que ele, em mim tinha, por sua doce e real clemência (1953: 9).

De modo parecido, porém falando a Isabel já como rainha, o franciscano Íñigo de Mendoza (1425-1507) e o jerônimo Hernando de Talavera também lhe endereçaram algumas orientações sobre como conduzir-se no regimento no reino. No Dechado, poema de 1475, escrito na forma de 42 coplas de pé quebrado, o frei franciscano apresentava as suas motivações, ao preparar tal poema dizendo à rainha na terceira estrofe:

\footnotetext{
Por isso, rainha excelente,

muito prudente,

determina minha rudeza

de servir a vossa alteza

sem preguiça

com este rude presente,

no qual minha mão atenta

e se afronta

a preparar-vos um modelo

de onde possa ser sacado

e preparado

o modo com que a gente

governeis discretamente.
}

Se foi como presente que o frei franciscano ofertou seus conselhos de governo à rainha, falando-lhe através da analogia que criou entre o molde - pano que servia de 
modelo (dechado) para o bordado e a costura das mulheres - e as instruções de governo que lhe havia preparado para servir de exemplo na tessitura do governo, Hernando de Talavera apresentou suas recomendações, em 1476, como peça sermonária adaptada ad usum reginae na Colación muy provechosa. Ou seja, se o franciscano tinha apresentado seus conselhos recorrendo à metáfora têxtil, o jerônimo dizia atender às expectativas espirituais e de governo de Isabel, ao ajustar uma peça homilética, destinada aos clérigos no início do tempo litúrgico do Advento, na qual lhes falava sobre a necessidade da renovação moral à maneira de uma águia ${ }^{4}$, a um programa moral que auxiliasse e iluminasse o coração da monarca no regimento e governo do reino. Como salientou o jerônimo, no prólogo deste sermão, ele havia acatado a demanda da monarca, escrevendo-lhe o conteúdo dessa prédica para que ela o pudesse ler individual ou coletivamente e conseguisse se renovar moralmente, a exemplo da águia, "rainha das aves", a quem São João Evangelista, patrono da rainha ${ }^{5}$, era comparado. Atendia-lhe este pedido para que lograsse "coração ensinado e simples de ensinar para julgar o povo e para discernir entre o bem e o mal" (2014:104).

Não obstante estes clérigos tenham recorrido a metáforas diferentes (o jardim das donzelas, o molde de costura e à águia), pode-se notar que eles perseguiram um propósito comum: orientar D. Isabel acerca de suas funções como rainha e, de certo modo, conceder-lhe legitimidade na sucessão e no regimento do reino. Ademais, o preparo sob as demandas da monarca da Colación é representativo de que também ela aspirava ser aconselhada nesse sentido e havia concedido auspícios a esse tipo de recomendação.

Como a expectativa de assumir a coroa era contemplada apenas por Isabel e aqueles que a apoiavam quando Martín de Córdoba lhe ofereceu o Jardín de nobles doncellas (1468) é possível notar, nesse espelho, um maior empenho, especialmente se comparado com os outros espelhos dedicados à Isabel já rainha, de legitimar e consolidar os seus poderes tendo em conta sua condição mulheril. Nem Íñigo de Mendoza, nem Hernando de Talavera revelam em suas obras a preocupação em investir inicialmente na defesa de todas as mulheres para só depois orientar Isabel acerca da governação do reino. Razão pela qual, as reflexões feitas pelo frei agostiniano merecerão maior atenção. 
O percurso que trilharia em sua obra é delineado a partir da retomada da tópica dos regimentos de príncipes de que o governo dos reis era uma concessão divina que exigia deles a observância do regimento de si, da casa e do reino. É essa tópica que Martín de Córdoba retoma para defender os direitos sucessórios de Isabel e ilustrar a "sabedoria moral" da futura rainha: inicialmente propunha falar-lhe a respeito das condições naturais das mulheres; na sequência, ensinar-lhe a discernir os bons dos maus costumes e, por fim, mostrar-lhe, através dos exemplos das mulheres passadas tomados dos textos bíblicos, dos pais da igreja e das referências dos antigos -, quais modelos deveria imitar. Organizava assim o seu texto, seguindo não apenas a tradição escolástica que previa a proposição de uma questão, o esgotamento de argumentos e posterior retomada do assunto para adentrar a uma nova problemática, mas também um recurso muito comum entre os studia humanitatis: o uso da citação e do exemplo para conceder autoridade, sustentação e caráter pedagógico aos argumentos defendidos (NARRO SÁNCHEZ, 2012; 6) .

O frade agostiniano preocupou-se inicialmente em retomar no Jardín algumas passagens bíblicas do livro do Gênesis, a fim de explicar algumas questões controversas acerca da natureza e condição das mulheres. Empenhou-se, inclusive, em mostrar certas características naturais delas que colocavam em evidência o que Deus tinha planejado a elas quando operou a obra da criação e o que lhes tinha determinado como castigo após a queda. ${ }^{6}$ Da costela, e não de outra parte do corpo de Adão, Deus teria criado as mulheres, pois, segundo o frade, isso era representativo do lugar que elas deveriam ocupar junto do varão: "nem senhora, nem serva", mas sim "sua companheira no matrimônio". Por elas terem sido feitas desse material, muitas semelhanças poderiam ser percebidas entre ele e as características delas. Mole, fraco e capaz de emitir muito barulho, quando dispostos em um recipiente e remexidos, os fragmentos da costela encontravam paralelo na "alma suscetível aos desejos e às vontades" delas, bem como na capacidade que tinham de "falar mais que os homens" (CÓRDOBA: 16-17). No entanto, Martín de Córdoba fazia um alerta a respeito dessa questão. Destacava que, embora esta interpretação insinuasse que as mulheres tinham "má propriedade", sobretudo pela associação que podia ser estabelecida entre elas e a "mãe Eva", também a Virgem Maria tinha suas origens numa costela. Por isso, se de uma parte considerasse que Eva era o motivo do vitupério das mulheres, visto que era a "costela" que havia se 
deixado conduzir pelo "demônio" e feito Adão pecar, de outra, lembrava que da Virgem Maria derivava o imperativo de que elas fossem louvadas, dado que a mãe de Cristo era a "costela" responsável por ter "prendido o Diabo" (CÓRDOBA: 16-21).

Quer dizer, segundo as considerações do clérigo, conquanto as mulheres fossem inclinadas naturalmente a alguns vícios, elas estavam, do mesmo modo, aptas a emendálos. Seus pecados tinham encontrado redenção na Virgem Maria. Todavia, respaldandose em Santo Agostinho, o clérigo dizia existir um propósito maior conduzindo-as depois que, em virtude do pecado inicial, foram expulsas do estado paradisíaco: cuidar da "multiplicação da linhagem humana"; "evitar a fornicação" através do matrimônio; e, "especialmente entre os reis", ou seja, no caso das princesas e rainhas, promover a paz e o entendimento dos reinos através das alianças matrimoniais (CÓRDOBA: 16-17). Em suma, caso se esforçassem, elas seriam capazes de alcançar as virtudes, ainda que sem poderem abster-se dos sofrimentos das dores do parto, da responsabilidade da vida conjugal e da sujeição à vontade de seus maridos e pais. ${ }^{7}$

Considerados estes pontos relativos à natureza e ao propósito divino da criação das mulheres - os quais representavam a recuperação da tópica, já comum em Castela desde o reinado de Juan II, de conceder, através da escrita, um espaço importante à defesa das mulheres a partir das menções à origem divina delas -, o frei agostiniano passava à proteção específica de Isabel. A ela dizia que, segundo Aristóteles havia anunciado na Retórica, "as mulheres tinham algumas condições boas e outras não boas", ou seja, a elas eram reputados vícios e virtudes característicos, por isso alertavalhe a respeito da necessidade de conhecê-los para que pudesse agir corretamente. Partindo, pois, da defesa das potenciais virtudes ou propensões de todas as mulheres, Martín de Córdoba buscava salvaguardar as virtudes exigidas à rainha, isto é, a uma mulher específica. Apresentava, desse modo, as pautas de comportamento que deveriam ajustar as ações de Isabel. Dizia-lhe que, enquanto a vergonha, a piedade e o obséquio outorgavam bondade às mulheres; a intemperança, a fala excessiva, a porfia e a inconstância atribuíam-lhe uma condição "não tão boa" (CÓRDOBA: 43).

Embora todas as virtudes próprias das mulheres apontadas pelo clérigo derivassem de alguma fraqueza ou debilidade mulheril, ele as considerava importantes por dois motivos: algumas dessas virtudes tinham a capacidade de catalisar outras e, ao mesmo tempo, impedir que alguns vícios fossem acionados nas mulheres. Por frear os 
apetites da jovem idade, impulsionar a honestidade e preservar a castidade, a vergonha, ainda que derivasse da fraqueza e do temor das mulheres, era importante para as donzelas, especialmente para as princesas, pelo fato de que estas se casariam com príncipes e reis e, segundo Martín de Córdoba, estes primeiramente "pesquisam sobre a esposa é se é honesta, virtuosa e composta de vergonha”. Além desta virtude da vergonha, que lhes auxiliava a frear a língua, a vestir "trajes que cobrissem suas cabeças e peitos" (CÓRDOBA: 44-46) para que nada sugerisse desonestidade, emendava o frei, a piedade, própria de quem tinha corpo fraco, era-lhes uma condição natural e ninguém mais do que a princesa deveria ser: "mãe, advogada e escudo" dos povos de seu reino. Assim como a mãe deveria ser naturalmente piedosa com seus filhos, a rainha ou princesa, que "também era mãe de seus povos", deveria ser piedosa com seus súditos. Deveria, ademais, defendê-los diante de qualquer ato tirânico do rei, bem como proteger os "humildes trabalhadores, os devotos oradores, os estudiosos mestres e doutores, as viúvas, os órfãos e os pobres sem amparo", daqueles que lhes eram superiores no reino (CÓRDOBA:50). Como também eram naturalmente obsequiosas, pelo fato de que "demandavam menos razão que os homens", era comum que se entregassem inteiramente à devoção divina, à compaixão ao próximo e aos cuidados da casa. Por isso, o frei dizia à princesa que como the era exigido, mais do que a qualquer outro, mostrar-se obsequiosa, servindo de exemplo a todos, louvando a Deus e defendendo a Igreja. Era-lhe indispensável, entre outras coisas: ir à missa todos os dias, rezar, ouvir sermões e as palavras de Deus, pedir que lhe fossem feitas leituras honestas durante as refeições, conversar com letrados e sábios sobre a doutrina divina e pensar sempre na outra vida (CÓRDOBA, 52). Sugeria-lhe ainda, cuidar dos enfermos, peregrinos, das donzelas e dos servidores de sua casa, bem como honrar seu marido e criar seus filhos em conformidade com os preceitos divinos. Em suma, que atenta-se para as referidas três esferas contempladas nos espelhos de príncipes como fundamentais da atuação dos governantes.

Somente depois de justificar a condição mulheril de Isabel e de lembrar-lhe de suas responsabilidades como mulher, esposa e mãe, é que o frei Martín de Córdoba passou a orientá-la mais detalhadamente sobre as exigências que lhe recaíam por ser rainha. Nesse aspecto, podem ser estabelecidos alguns paralelos e distanciamentos entre os apontamentos deste frade e aqueles realizados por Íñigo de Mendoza e Hernando de 
Talavera. A partir das noções aristotélicas repassadas aos medievais, sobretudo a partir dos regimentos de príncipes preparados por São Tomás de Aquino e Egídio Romano ${ }^{8}$, de que eram indissociáveis nos reis a moralidade de suas ações e suas práticas de governo, todos eles advertiram Isabel a respeito da relação entre o cuidado de si e do reino. Conforme salientou o frei agostiniano, maiores obrigações recaíam sobre a rainha porque ela, assim como o rei, era "lugartenente de Deus" e por isso devia se ordenar em "respeito a Deus, a si mesma e ao povo". Assim, se por um lado, devia mostrar amor e respeito a Deus pelo fato de que Ele lhe havia predestinado a ser "rainha de tão nobre reino como o de Espanha" (CÓRDOBA: 59-65), por outro, cabiam-lhe algumas obrigações de foro íntimo e outras relativas à condução do povo.

Íñigo de Mendoza, porque considerara a eleição de Isabel como efeito da graça divina, organizou o Dechado de maneira a associar as quatro virtudes cardeais (Justiça, Fortaleza, Temperança e Prudência), comumente exigidas aos reis e consideradas necessárias ao governo do reino, a certas práticas pessoais da rainha. De maneira parecida, Hernando de Talavera destacava, na Colaçión, que grandes encargos recaíam sobre aqueles que, como os reis, serviam a Deus. Dessa forma, enfatizava que lhes convinha, mais do que a ninguém, pensar como fariam com suas vontades, uma vez que, "grandes penas" encontrariam no inferno se fossem "negligentes e se esquecessem de seus cargos entregando-se aos deleites e prazeres" (TALAVERA, 2014: 107-108)

Tanto Martín de Córdoba como Íñigo de Mendoza advertiram Isabel sobre os cuidados de si, apontando alguns perigos que rondavam a vida cortesã, a saber: o amor desordenado, a riqueza, as pompas e os deleites carnais. Para ambos, Isabel, sustentando-se em seus gestos pessoais, deveria pôr fim aos comportamentos negativos que, naqueles tempos, rondavam a corte. Instigando Isabel a afastar-se dos amores furtivos, Martín de Córdoba destacava que, enquanto as mulheres más eram "arma do Cupido, que é o deus do amor", e conquistavam seguidores por meio de "furtivos olhares e de brandas palavras para ferir os corações dos varões e arrendá-los, as santas e boas eram arma e arco turco para matar o Cupido e os sujos amores" (CÓRDOBA:17). Íñigo de Mendoza, de maneira parecida, ao recomendar a Isabel a virtude da temperança, pedia-lhe que defendesse sua honra e fosse inimiga de amores, dizendo-lhe: 


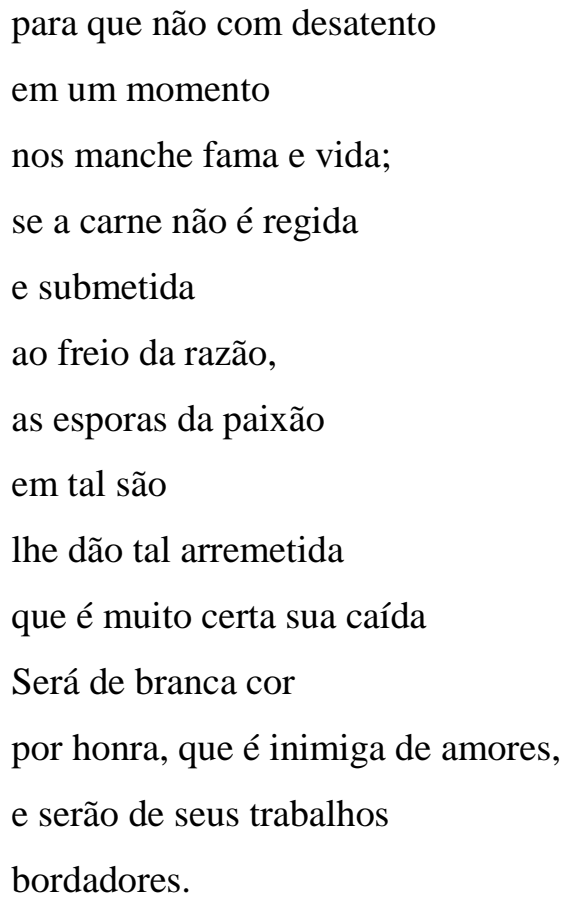

Lembrava ainda à rainha que muitos "maus recados" eram passados pelas cortes onde "damas e galãs soltos/ e revoltos/ como se fossem casados", transitavam "pelos cantos abraçados, / por estrados, / sem vergonha pela sala”. Ou seja, a rainha devia exercer o papel de reguladora da conduta moral nas cortes. Nestes espaços, cumpria-lhe atuar de maneira a afastar tudo que desonrasse a fama de seu séquito de damas e cavaleiros. Até mesmo porque, segundo advertiu Hernando de Talavera à rainha, em uma de suas missivas, por ter dado "licença para mesclar cavaleiros franceses com as damas castelhanas" durante um jantar, muita honra ficou ameaçada, pois os estrangeiros sairiam do reino carregando a imagem da "pouca honestidade e gravidade castelhana" (OCHOA, 1870:19). Isto é, as atitudes da rainha e de sua corte tinham impacto para além dos limites territoriais do reino, de forma que cabia à monarca não só assegurar a boa fama de sua corte entre os seus povos, mas ainda garantir que essa fosse a imagem repassada aos estrangeiros.

Às advertências ao desordenado amor juntavam-se, ainda, aquelas feitas aos gastos excessivos, ao exagero no ornamento das roupas e às brechas que estes descomedimentos abriam aos deleites carnais. Dos corações das princesas e rainhas deveriam ser arrancados os apetites por riqueza, honra e voluptuosidade, consoante lembrava Martín de Córdoba, pois, se de uma parte o "amor às riquezas" colocava seus corações em "terras sujas" e o "amor às honras os enchia de vaidade"; de outra, o 
“desejo da carnalidade" ocupava seus corações com "lodo e fedor" (CÓRDOBA: 63). Emendava o agostiniano que muito errava a mulher que procurava "parecer mais formosa do que era", não respeitando as formas de vestir condizentes com seu estado, já que suas vestes deveriam traduzir não só o estado a que pertenciam, mas inclusive a honestidade que estes estados requeriam. Íñigo de Mendoza, de maneira parecida, também chegou a advertir Isabel a respeito dos perigos do dinheiro, dizendo-lhe que o apreço pela riqueza era "coisa muito vergonhosa" e "Perigosa/ na pessoa real", dado que fazia muitos monarcas, por cegueira, se subjugarem a ele. Em função disso, dizialhe que pouca fortaleza demonstravam os reis que, instigados por acumular riqueza, cometiam atitudes viciosas. Nesse sentido, pedia à rainha, dentre outras coisas, equilíbrio e simplicidade na sua forma de vestir, pois suas damas poderiam repetir suas práticas e a honra de todas as mulheres, independentemente de seus estados, lograria ser acrescentada.

\author{
tanto sã \\ tens vós vossa limpeza \\ de vossa real alteza \\ não se reza \\ outra coisa neste ponto \\ senão que com muita vontade \\ à maneira simples \\ façais que vivam as damas, \\ porque à volta de suas famas \\ e suas tramas \\ a malícia castelhana \\ não digam qual é simples.
}

Para além do cuidado de si, Isabel foi instigada pelos clérigos a conceder especial atenção às virtudes necessárias à condução dos povos do reino. A esse respeito, Martín de Córdoba apontou-lhe as virtudes da justiça, liberalidade e afabilidade como essenciais para "dar boa ordem aos próximos e súditos" (CÓRDOBA:75). Íñigo de Mendoza igualmente indicou-lhe a justiça, mas, diferentemente do agostiniano, a essa virtude acrescentou a fortaleza, a temperança e a prudência. Retomando a tópica 
egidiana de que a justiça era a alma do reino, enquanto aquele que a exercia, isto é, o rei, representava a cabeça ${ }^{9}$, Martín de Córdoba lembrava Isabel de que, se ela quisesse impor "ordem entre seus súditos" e defender a "guarda de seu reino", deveria agir com justiça, dando "a cada um" o que era merecido, "segundo seus bons ou maus méritos"(CÓRDOBA:78). Em consonância com essa perspectiva, lembrava o frei franciscano à rainha que, para agir com justiça, impunha-lhe matar e punir os que tinham vida corrompida e, ao mesmo tempo, ter clemência e compaixão com os que mereciam perdão. Ao passo que a liberalidade e afabilidade eram, segundo Martín de Córdoba, associadas à equilibrada distribuição de benefícios aos povos e à cara amigável com que a rainha deveria receber os virtuosos; a fortaleza, temperança e a prudência vinculavam-se, consoante Íñigo de Mendoza, respectivamente: à firmeza e ao destemor diante dos interesses dos privados e dos gananciosos por dinheiro, à guarda da fama e à capacidade de ater-se ao passado para saber conduzir-se no presente. Hernando de Talavera, por sua vez, extraiu de algumas propriedades da águia os ensinamentos que julgou serem necessários à rainha, tais como: a liberalidade, a agudeza visual, a compleição quente e seca, a animosidade, a falta de ociosidade, a busca de amparo em lugares altos, a capacidade de proteger e educar seus filhos e a peculiar maneira com a qual esse animal se renovava constantemente, cortando seu bico e banhando-se. Partindo, pois, da alegoria moral da águia, o jerônimo lembrava à rainha que, a exemplo de São João, Abraão, São Paulo e Samuel, Isabel deveria saber dividir os benefícios do reino com seu povo. Citando Santo Isidoro e o Eclesiastes, instigava-lhe a ter olhar forte e agudo. Admoestava-lhe ainda a: conformar-se em tudo com a vontade divina; praticar a castidade e o amor a Deus; nunca ficar ociosa; repetir os exemplos de virtude do passado; corrigir e ensinar os súditos com rigor e, por fim, "renovar sua alma, procurando a perfeição" (TALAVERA, 2014:109-132).

Como é possível notar, conquanto estes clérigos tenham tentado estabelecer um modelo de rainha, ou seja, um conjunto de comportamentos destinados e dignos de serem reproduzidos por Isabel, eles levaram a cabo esta tarefa de maneiras diferentes. Mais próximo, no que diz respeito à forma e ao conteúdo dos specula principum e dos tratados em defesa das mulheres, o texto de Martín de Córdoba foi preparado para atender as urgências de defesa das mulheres e de legitimação dos direitos de uma futura rainha. Sem desconsiderar que alguns vícios eram inerentes à natureza mulheril, o 
agostiniano apresentou o Jardín a Isabel como uma espécie de "arte de fazer-se virtuosa", isto é, como compêndio de técnicas para auxiliar a jovem princesa a conduzir seus gestos e posturas de modo que estes confirmassem e estivessem à altura da posição que ela ocuparia no reino. Embora tenha levado em consideração e exaltado algumas virtudes comumente associadas às mulheres, como a castidade, a afabilidade e a vergonha - provavelmente porque tinha em mente os problemas e as amargas consequências que o questionamento acerca da castidade da rainha D. Juana havia trazido a Castela -, não negou que o esforço exigido à rainha, em virtude das cobranças de sua função, deveria fazê-la ultrapassar sua condição mulheril; ou seja, o posto de monarca requeria dela, até mesmo, ânimo varonil:

Pois a mulher que quer ser virtuosa há de consentir consigo e dizer: Eu sou mulher; e nisso não há culpa nenhuma, já que ser mulher me deu natureza assim como a outro ser varão; porém, pois que sou mulher, tenho que olhar os defeitos que comumente seguem as mulheres e me distanciar deles. As mulheres comumente são faladeiras: eu quero pôr porta à minha boca. As mulheres comumente são de pouca constância: eu quero ser firme em meu propósito, que outras foram antes de mim que tiveram grande constância; e por exemplo delas eu quero ser firme em virtude. E, se esta conjugação devem fazer todas as mulheres, muito mais a princesa, que é mais que mulher, e em corpo mulheril deve trazer ânimo varonil (CÓRDOBA: 87).

Quer dizer, para vencer os vícios comuns às mulheres, Martín de Córdoba propunha a Isabel que tivesse, tal como os homens, esforço e determinação. Lembravalhe que, "ainda que fosse fêmea por natureza", deveria trabalhar para ser "varão em virtude". Ora, ser varão em virtudes significava, em grande medida, contrapor-se aos vícios comumente praticados pelas mulheres, mostrar-se equilibrada e cuidadosa com as exigências de suas funções, apresentar-se como a mais excepcional das mulheres, já que o lugar que ocuparia no reino obrigava-lhe a ser digna de ser imitada pelas outras donzelas e senhoras castelhanas. Por isso, o frei indicava-lhe, recordando algumas mulheres exemplares compendiadas por Juan Rodríguez Del Padrón, Diego de Valera e Álvaro de Luna, as lições de castidade e honestidade dadas por donzelas, viúvas e casadas, tais como: Santa Pelágia, Santa Brígida, Márcia, Marcela, Júlia, Pórcia, dentre outras senhoras do passado. Para o agostiniano, somente a castidade dava fama imortal às mulheres. Levando em consideração que o agostiniano associou as tarefas de governo de Isabel ao cuidado maternal com os súditos, à salvaguarda da Igreja e à mediação 
entre o povo e o rei, parece que não se encontrava no seu horizonte de expectativa que ela fosse atuar como rainha proprietária, mas, sim, que ela desempenharia as funções comumente exercidas pelas rainhas consortes (RÁBADE OBRADÓ, 2004: 75).

Diferentemente de Martín de Córdoba, que escreveu a Isabel quando ela era ainda princesa, Íñigo de Mendoza e Hernando de Talavera escreveram-lhe no momento em que sua titularidade de rainha já não era mais uma promessa, mas uma constatação. Embora o frei franciscano tenha falado à rainha no Dechado, partindo de referências ao universo mulheril, tais como os elementos relativos aos afazeres do bordado e da costura, diferente do frei agostiniano, ele não dialogou com uma nobre donzela, antes se dirigiu a uma rainha em exercício, capaz de ocupar o trono, exibir a coroa e cumprir as funções de governo com o mesmo rigor de um varão. Não obstante Íñigo de Mendoza tenha compartilhado com Martín de Córdoba o empenho em encorajar Isabel a romper com os hábitos viciosos da corte de Enrique IV, notadamente aqueles relativos aos escândalos morais e ao mau uso do dinheiro, não foi do seu interesse discutir sobre a condição mulheril da rainha. Ele se importou, ao contrário, em sobrepor a função da monarca à sua condição de mulher. Assim, como comumente era exigido dos reis o cumprimento das quatro virtudes cardeais, o franciscano reforçou a capacidade da monarca para fazer justiça, agir conduzida pela temperança e fortaleza, bem como para se guiar pelos caminhos da prudência. Falou, pois, à rainha como se estivesse se referindo a um rei.

Hernando de Talvera também escreveu a Isabel quando ela já se encontrava no exercício de suas funções. Sua Colacçión, por exemplo, tratou-se de uma adaptação do sermão proferido por ele, provavelmente em Valladolid, para atender às demandas espirituais e aos anseios por orientação governativa da rainha. Como os clérigos compunham inicialmente o público para o qual eram dirigidas as orientações do frei jerônimo e a temática da homilia girava em torno da urgência de os religiosos se prepararem para o tempo litúrgico do Advento, são notáveis na Colaçión, sobretudo se comparada ao Jardín e ao Dechado, os apelos ao sagrado. Integrando a monarca ao público dessa obra, Talavera a orientava a buscar nas propriedades da águia as diretrizes para alcançar perfeição moral e para atender às exigências de sua condição de rainha. Partindo da associação que podia ser estabelecida entre a rainha das aves, isto é, a águia, animal associado a São João Evangelista, e a monarca, o jerônimo destacava a 
sacralidade do ofício régio. Somente aos clérigos e aos monarcas, pelo alto lugar que ocupavam junto a Deus e perante os povos, nas palavras de Hernando de Talavera, cabia a comparação com essa ave. Tal como ela, clérigos e reis "ensinavam seus filhos a voar" (TALAVERA, 2014: 108). Por isso, o jerônimo considerava tão importante que os reis e as rainhas buscassem não só referência nas propriedades da águia, mas também nos exemplos do passado, especialmente bíblicos. Recomendava a Isabel que criasse e educasse seus filhos seguindo "as boas obras e os nobres costumes", que se mirasse nos exemplos de "reverência e acatamento" de Sara, na "vergonha e recolhimento" de Rebeca, na "devoção e contemplação" de Raquel, na "benignidade, graça e liberalidade" de Abgail, "na humildade de entendimento e de obra" da rainha Ester, dentre outras mulheres do antigo testamento (TALAVERA: 126-127). Da mesma maneira que Martín de Córdoba, Talavera recorreu à exemplificação para ensinar à rainha quais virtudes ela deveria imitar, no entanto, distinguindo-se dele e também de Íñigo de Mendoza, não se dirigiu a ela como se estivesse diante de uma jovem donzela, nem mesmo de uma mulher com ânimo varonil, mas sim, de uma "dona e senhora tão perfeita e cheia de toda virtude e bondade como entre as aves é a águia”. Logo, pode-se dizer que as recomendações dos mencionados clérigos sugeriam a Isabel que ela, pelo fato de ser rainha, se apresentasse ou como uma mulher excepcionalmente virtuosa e/ou com ânimo varonil.

Com efeito, as referências às virtudes da Virgem e ao exemplo mariano para indicar como Isabel deveria se portar, ou mesmo para exaltar seu alto lugar e excepcionalidade, são significativos em todos os citados regimentos escritos pelos clérigos, assim como em certas missivas endereçadas à rainha por alguns laicos. No Jardín, Martín de Córdoba lembrava a Isabel que, se todos os fiéis deveriam seguir os exemplos de castidade, pureza, paciência e piedade evidenciados pela mãe de Cristo, especialmente a princesa deveria segui-los por três motivos em especial: ela era de "linhagem real, tal como a Virgem foi filha de reis", "donzela como era a Virgem quando concebeu o filho de Deus" e porque esperava "ser rainha, tal como a Virgem, Rainha dos céus, senhora dos anjos, mãe dos pecadores e manto de todos os fiéis" (CÓRDOBA: 21). Hernando de Talavera, de sua parte, na Colaçión, dizia a Isabel que "sobre todas e entre todas" as mulheres ela deveria "fazer cama e leito, estrado e ninho nas virtudes da Rainha das rainhas e Senhora dos anjos e dos céus, a Virgem gloriosa”. 
No modelo de Maria, ela era instigada pelo jerônimo a encontrar a "perfeitíssima humildade e a mais perfeita misericórdia" (TALAVERA: 127). Ao passo que, para esses freis, alguns paralelos entre as vidas e as funções de Isabel e Maria pudessem ser estabelecidos e fossem imperativo de que as virtudes da mãe de Cristo seriam seguidas, antes de todos, particularmente pela rainha, o frei franciscano, Íñigo de Mendoza, chegou a comparar claramente Isabel à Virgem:

\author{
Alta rainha esclarecida, \\ Guarnecida \\ de grandezas muito reais, \\ a remediar nossos males \\ Desiguais \\ pela graça de Deus vinda, \\ como quando foi perdida \\ nossa vida \\ pela culpa de uma mulher, \\ nos quer Deus guarnecer \\ e refazer \\ por aquele modo e medida \\ que levou à nossa caída.
}

Nas palavras do frei franciscano, assim como Maria tinha recebido a missão de redimir os pecados de Eva, Isabel, pela graça de Deus, tinha sido colocada no caminho dos castelhanos para remediar-lhes os males e redimir-lhes dos pecados.

Outros escritores laicos, também lançaram mão dessa imagem da rainha Isabel. Diego de Valera, em uma das epístolas que encaminhou à rainha, chegou a dizer que "assim como nosso Senhor quis que neste mundo nascesse a gloriosa Senhora nossa, para que dela procedesse o universal Redentor da linhagem humana", também a rainha tinha nascido para "reformar e restaurar" o reino, livrando-o de toda "tirânica governação" (VALERA, 1878: 46). Do mesmo modo, porém ampliando a área da atuação restauradora da monarca, Pedro Martír de Anglería, em uma de suas cartas, investindo Isabel de tal perfil reformador, havia declarado que, "como Maria remediou a 
humana linhagem, encarregando seu filho Deus" de redimir a todos, assim Isabel, "com suas virtudes, remediou a Espanha e toda Europa". Até mesmo Cassandra de Fedele (1465-1558), uma jovem poeta e letrada veneziana com quem Isabel trocou cartas entre 1487 e 1497, se dizia seduzida e entusiasmada, assim como outros letrados, a descrever as "virtudes" e "os atos extraordinários" da rainha, por considerá-los mais "divinos" do que "humanos" (ROBIN, 2000: 19-23).

Alguns desses mesmos letrados, igualmente enfatizaram o caráter extraordinário de Isabel, só que a partir de suas qualidades varonis. A esse respeito dizia Pedro Martír de Anglería na carta que enviou a Pomponio Leto em 23 de março de 1488:

É esta mulher mais forte que um varão forte, mais constante que toda alma humana, maravilhoso exemplo de honestidade e pudor, semelhante à qual nunca a Natureza fez outra mulher. Não é, pois, admirável, oh Pomponio! Que aquelas qualidades alheias à mulher - como termos opostos - se encontrem nesta como nativas e amplificadas? (1953:10-11)

Em outra carta enviada a Ascanio Visconti, datada de 1 de agosto de 1488, novamente se dizia surpreendido pelo incomparável valor de Isabel e por ela ter superado sua condição mulheril:

A meu juízo, esta mulher não se pode comparar com nenhuma das Rainhas louvadas pela antiguidade: é valorosa, grande e digna de elogio em suas empresas. Costumam as mulheres, em sua maioria, revestir-se de uma invencível firmeza para o mal. Esta é mais constante que a mesma constância, o que é de todo contrário à fragilidade da mulher, animal imperfeito (1953:40).

Cassandra de Fedele, de modo parecido, fazia alusão à força de ânimo da monarca ao converter Isabel na capitã dos exércitos contra os bárbaros, na soberana que havia garantido a sobrevivência do nome cristão, ao expulsar os infiéis, ou seja, ao descrever Isabel como uma mulher guerreira, tal qual uma amazona clássica (SEGARRA AÑON, 2011:284). 


\section{Conclusões}

A partir das recomendações feitas pelos clérigos nos espelhos de princesa endereçados a Isabel e das descrições que dela fizeram também outros letrados, podemos perceber que, em muitos casos, a solução encontrada por eles para dar conta da dissonância entre a natureza mulheril e o exercício de governo foi, por vezes, ressaltar a excepcionalidade das circunstâncias e características de Dona Isabel, ou mesmo, investir nas suas qualidades varonis. A incompatibilidade entre as exigências das funções relativas ao regimento do reino e as características que se consideram próprias da natureza das mulheres foram explicadas por aqueles que discutiram sobre essa questão, pela ênfase dada à exceção ou mesmo à anomalia (NIETO SORIA, 2006).

Como é possível observar, as circunstâncias que haviam dado a D. Isabel, um protagonismo decisivo nos jogos de poder do reino castelhano, intensificaram o interesse já perceptível em Castela, sobretudo desde o reinado de Juan II, pela representatividade social das mulheres, maiormente das rainhas. As disputas sucessórias entre D. Isabel e sua sobrinha, D. Juana, colocaram no alvo das discussões tanto o tema da legitimidade de direito hereditário pela via das mulheres, como a capacidade governativa delas. Se na corte de Juan, os novos hábitos da vida cortesã relativos ao amor, às festas e aos ideais de cavalaria tinham motivado alguns letrados a colocarem suas plumas a serviço da defesa das mulheres, na corte de Enrique IV, filho deste rei, estas mesmas práticas e costumes envolvendo as damas do reino tinham fundamentado o vitupério de D. Juana e das mulheres de sua corte. As dúvidas a respeito da castidade e moralidade dessa rainha tinham colocado em perigo o regimento e dado ensejo a uma crise sucessória no reino. Diante da difamação e dos escândalos que recaíram sobre a esposa de Enrique IV, D. Juana, e demais mulheres da corte, atribui-se àquela que foi sucessora da coroa, D. Isabel, uma empreitada moralizante no reino. 


\section{Fontes e referências bibliográficas}

\section{Fontes}

CÓRDOBA, M. Jardín de nobles doncellas. Introdução de Padre Felix García. Madri: Coleção Joias Bibliográficas, 1953.

VALERA, D. Epístola que Mosen Diego de Valera enbió á la Reyna Nuestra Señora. In: Epístolas de Mosen Diego de Valera enviadas en diversos tiempos e a diversas personas juntamente con otros cinco tratados del mismo autor. Madri: Sociedad de los Bibliófilos Españoles, 1878.

MARTÍR DE ANGLERÍA, P. Epistolario. In: LÓPEZ TORO, J. (Ed.). Documentos inéditos para la historia de España. Edição de José López Toro. Madri: Imprenta Gongora, 1953.

MENDOZA, Í. Dechado que hyzo frey Yñigo de Mendoça a la muy excelente reyna doña Ysabel, nuestra soberana señora. Alicante: Biblioteca Virtual Miguel de Cervantes, 2002. s/p. Disponível em: <http:/www.cervantesvirtual.com/obra-visordin/dechado-que-hizo-frey-ynigo-de-mendoca-a-la-muy-escelente-reyna-dona-ysabelnuestra-soberana-senora--0/html/ff9224fc-82b1-11df-acc7-002185ce6064_2.html\#I_0 > Acesso: 29 set. 2019.

OCHOA, E. Epistolario Español. Colección de cartas de españoles ilustres antiguos y modernos. Madri: Imprenta y estereotipia de M. Rivadeneyra, 1870, t. II. p. 19.

PEREZ DE GUZMÁN, F. Generaciones y Semblanzas. Edição e notas de J. Domínguez Bordona. Madri: Espasa-Calpe, S.A, 1941.

TALAVERA, H. Colación muy provechosa. In: PARRILLA, C. (Ed.). Hernando de Talavera. Dos escritos destinados a la reina Isabel. Colación muy provechosa. Tratado de loores de San Juan Evangelista. Valencia: Universitat de València, 2014.

\section{Bibliografia}

ÁlVAREZ PALENZUELA, V. A. María, infanta de Aragón y reina de Castilla. In: Estudos em Homenagem ao Professor Doutor José Marques. Porto: Faculdade de Letras da Universidade do Porto, v. 4, p. 370, 2006.

BECEIRO PITA, I. La mujer noble en la Baja Edad Media castellana. In: FONQUERNE, Y-R; ESTEBAN, A. (Coord.). La condición de la mujer en la Edad Media. Actas del coloquio celebrado en la Casa de Velázquez del 5 al 7 de noviembre de 1984. Madri: Casa de Velazquez, Universidad Complutense, 1986. 
CARRASCO MANCHADO, A. I. La metáfora animal en la propaganda política de los Reyes Católicos (1474-1482). Cahiers de linguistique et civilisation hispaniques médiévales, França, 2002.

CODET, C. Femmes et éducation en Espagne à l'aube des Temps Modernes (1454-fin desannées 1520). 2014. f. 770.Tese (Doutorado) - École normale supérieure de Lyon, Lyon, 2014.

HARO CORTÉS, M. Mujer, corona y poder en espejo de princesas: El Jardín de nobles doncellas de fray Martín de Córdoba. In: CELMO VALERO, M. P; RODRÍGUEZ PEQUEÑO, M. (Ed.). Vivir al Margen. Mujer, poder e institución literaria. Burgos: Instituto Castellano y Leonés de la lengua, 2009.

FÉLIX BELLIDO, J. Razones de una mujer. Memorias autobiográficas de Leonor López de Córdoba. Córdoba: Alamendro, 2012.

GUIMARÃES, M. L. As memórias de D. Leonor López de Córdoba (1362/631430): uma poética do não esquecimento. Mirabilia, n.21, 2015.

NARRO SÁNCHEZ, A. Tradición clásica en el Jardín de Nobles donzelas de Fray Martín de Alonso de Córdoba. Calamus Renascens, Espanha, n. 13, p. 6, 2012.

NIETO SORIA, J. M. Ser reina. Un sujeto de reflexión en el entorno historiográfico de Isabel la Católica. e-Spania. Governer en Castille au Moyen Âge: la part des femmes, 1 jun. 2006. Disponível em: $<$ https://e-spania.revues.org/327 $>$. Acesso em: 25 abr. 2019.

NOGALES RINCÓN, D. Los espejos de príncipes en Castilla (siglos XIII-XV): Un modelo literario de la realeza Bajomedieval. Medievalismo, Espanha, n. 16, p. 9-39, 2006.

RÁBADE OBRADÓ, M. P. Ética y Política: recomendaciones de Fray Martín Alonso de Córdoba a la futura Isabel I. In: LÓPEZ-CORDÓN, M. V; FRANCO RUBIO, G. (Coord.). La reina Isabel I y las reinas de España: realidade, modelos e imagen historiográfica. Actas de la VIII Reunión Científica de la Fundación Española de Historia Moderna, 2-4 jul. 2004. Espanha: Fundación Española de Historia Moderna, 2005.

ROBIN, D. (Ed.). Cassandra de Fedele. Letters and orations. Chicago: The University Chicago Press, 2000.

SEGARRA AÑON, M. I. Bajo la somba de tus alas. Isabel la católica y Cassandra de Fedele. Miscelánea Comillas, Espanha, v. 69, n. 134, p. 284, 2011.

SORIANO, C. Conveniencia política y tópico literario en el Jardín de Nobles Doncellas (1468?) de Fray Martín Alonso de Córdoba. In: LUCÍA MEGÍAS, J. M. Actas del VI Congreso Internacional de la Asociación Hispánica de literatura medieval. Alcalá de Henares: Servicios de publicaciones de la Universidad de Alcalá, 1997, t. II, p. 1460 .

\footnotetext{
${ }^{1}$ Esse artigo é parte da pesquisa de Doutorado que desenvolvi entre os anos de 2012 e 2016 com o financiamento da Fundação de Amparo à Pesquisa do Estado de São Paulo (FAPESP).

${ }^{2}$ Frei agostiniano, Martín de Córdoba foi docente nas universidades de Salamanca e Toulousse, vigário da ordem de Santo Agostinho em Salamanca. Além do Jardín de nobles doncellas preparou um
} 
Compendio de la Fortuna (dedicado a Álvaro de Luna). Pouco se sabe sobre as relações que o frei teria mantido com Isabel. Possivelmente ele integrou a corte que se formou em torno de Afonso quando este foi alçado rei em Ávila e apoiou Isabel, depois da morte de seu irmão. Para maiores informações consulte: HARO CORTÉS, M. Mujer, corona y poder en espejo de princesas: El Jardín de nobles doncellas de fray Martín de Córdoba. In: CELMO VALERO, M. P; RODRÍGUEZ PEQUEÑO, M. (Ed.). Vivir al Margen. p. 45.

${ }^{3}$ Cogitou-se a possibilidade de Martín de Córdoba ter sido chamado por Isabel de Portugal para compor a educação de Afonso e Isabel, no entanto, não há nenhum vestígio documental sobre isso. Também não há nada que confirme que o frei e Isabel tenham tido uma relação pessoal, embora seja claro o empenho do frei em legitimá-la como rainha. Maiores detalhes em: SORIANO, C. Conveniencia política y tópico literario en el Jardín de Nobles Doncellas (1468?) de Fray Martín Alonso de Córdoba. In: LUCÍA MEGÍAS, J. M. Actas del VI Congreso Internacional de la Asociación Hispánica de literatura medieval. Alcalá de Henares: Servicios de publicaciones de la Universidad de Alcalá, 1997, t. II, p. 1460.

${ }^{4}$ Aos animais foram dados, conforme indicam as análises feitas acerca dos bestiários, tratados escolásticos e das enciclopédias, caráteres de alegoria moral e simbologia profética. Durante o reinado dos católicos, muito se recorreu a eles para exaltar nos monarcas algumas virtudes e a marca divina, ademais, eles tiveram relevante participação em alguns cerimoniais. Segundo os apontamentos de: CARRASCO MANCHADO, A. I. La metáfora animal en la propaganda política de los Reyes Católicos (1474-1482). Cahiers de linguistique et civilisation hispaniques médiévales, França, p. 402, 2002.

${ }^{5} \mathrm{O}$ interesse e a devoção da rainha a São João Evangelista teriam motivado a escrita de tratados e poesias em louvor a este santo. Hernando de Talavera preparou à monarca um Breve Tratado de Loores del bienaventurado san Juan Evangelista. Frei Ambrosio de Montesino, de sua parte, ofereceu a Isabel Al sol vence con tus vistas e Razón tiene vuestra alteza.

${ }^{6}$ Segundo apontam alguns estudos, dentre as fontes que teriam alimentado o texto de Martín de Córdoba destacam-se: o Triunfo de las donas, Libro de las virtuosas e claras mugeres e o Tratado em defensa de virtuosas muges. Para maiores informações: NARRO SÁNCHEZ, A. Tradición clásica en el Jardín de Nobles donzelas de Fray Martín de Alonso de Córdoba. Calamus Renascens, Espanha, n. 13, p. 5, 2012.

${ }^{7}$ Embora as mulheres devessem ser obsequiosas a seus maridos, as rainhas, assim como as altas donas que tinham seu estado a parte de seus cônjuges, não deviam a eles total benevolência. "[...] a mulher há de ser obsequiosa ao marido, amando-o, honrando-o e por si e por outras, servindo-o. É verdade que isto não cabe às altas donas que têm seu estado a parte de seus maridos. Isto, ainda que não seja sempre, porém ao menos quando queira e convenha, a dona deve estes obséquios a seu senhor e marido". CÓRDOBA, M. Jardín de nobles doncellas, p. 53. Sobre este tema ver: BECEIRO PITA, I. La mujer noble en la Baja Edad Media castellana. In: FONQUERNE, Y-R; ESTEBAN, A. (Coord.). La condición de la mujer en la Edad Media. Actas del coloquio celebrado en la Casa de Velázquez del 5 al 7 de noviembre de 1984. Madri: Casa de Velazquez, Universidad Complutense, 1986. p. 289-313.

${ }^{8}$ Referimo-nos às reflexões aristotélicas realizadas na Política e na Ética a Nicômaco e à apropriação dessas considerações, ainda que de forma específica, por São Tomás de Aquino, no De Regno (1267), e por Egídio Romano, no Regimento de Príncipes (1285). Textos, estes, que serviram, a partir do século XIII, como parâmetro de governo para os reis medievais.

${ }^{9}$ Egídio Romano, no Regimento de Príncipes, partindo de Aristóteles, destacava que o rei era a justiça animada e a partir dele todos os povos do reino deveriam buscar orientação. $\mathrm{Na}$ glosa desse regimento realizada pelo frei Juan García de Castrojeriz, o mesmo recorre a Cícero, a Santo Agostinho e a Valério, para apresentar exemplos de bons reis que agiram com retidão e justiça. 